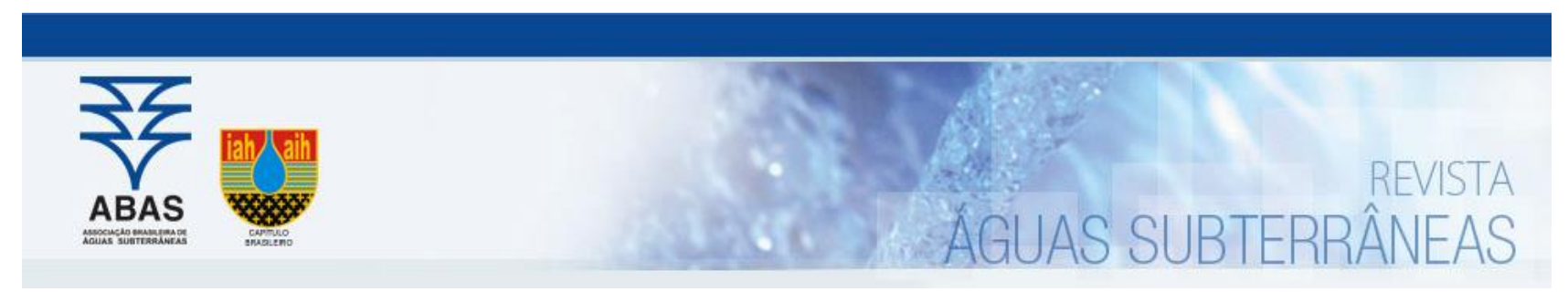

Artigos

\title{
Avaliação da qualidade da água para consumo humano prove- niente de poços rasos e do risco de infecção desta por exposi- ção a patógenos emergentes em um bairro de Goiânia, Goiás
}

\section{Evaluation of the quality of water for human consumption from shallow wells and the risk of infection due to exposure to emerging pathogens in a neighborhood of Goiânia, Goiás}

\author{
Marília Honorato Moreira1; Katia Alcione Kopp; Adelaide Cassia Nardocci2 ${ }^{\bowtie}$ \\ 1 Universidade Federal de Goiás (UFG), Goiânia, GO \\ 2 Universidade de São Paulo (USP), São Paulo, SP.
}

凶mariliahhonorato@gmail.com, kakopp@ufg.br, nardocci@usp.br

Palavras-chave:
Água subterrânea;
AQRM;
Giardia.
Cryptosporidium;
Campylobacter.

Campylobacter.

Keywords:

Groundwater;

MRQA;

Giardia;

Cryptosporidium;

Campylobacter.

Revisão por pares.

Recebido em: 26/05/2021.

Aprovado em: 06/09/2021.

\begin{abstract}
Resumo
A análise da água permite levantar informações que garantam segurança hídrica e prevenção de doenças de veiculação hídrica. O presente estudo visou a avaliar a qualidade da água e empregar a Avaliação Quantitativa de Risco Microbiológico (AQRM) como uma ferramenta para definir o risco de infecção, associado à exposição a patógenos emergentes na água subterrânea de um bairro da Região Sudoeste de Goiânia. Foram analisadas amostras de água de 30 pontos em relação aos parâmetros físico-químicos e microbiológicos. A AQRM foi obtida por meio de abordagens nas etapas de identificação do perigo, na avaliação da exposição, avaliação dose-resposta e caracterização do risco de infecção. Os resultados demonstraram que a água subterrânea do bairro não está de acordo com os padrões de potabilidade, principalmente referente aos parâmetros microbiológicos, que em todas as amostras apresentaram valores fora do limite estabelecido pela legislação. A AQRM mostrou valores de risco anual elevados, acima do limite definido pela U.S. Environmental Protection Agency (EPA) para exposições que ocorrem com a ingestão de água. 0 estudo evidenciou a urgência de se estabelecer ações de gerenciamento de risco para a água do local estudado. Adicionalmente, medidas de conscientização da população local, por meio de programas ou projetos de educação ambiental, podem ser importantes para que os moradores entendam os riscos de se consumir a água dos poços rasos sem nenhum tratamento.
\end{abstract}

\section{Abstract}

The analysis of water allows gathering information to ensure water security and prevention of waterborne diseases. This study aimed to assess water quality and employ the Microbiological Risk Quantitative Assessment (MRQA) as a tool to define the risk of infection associated with exposure to emerging pathogens in the groundwater of a neighborhood in the Southwest Region of Goiânia. Water samples from 30 points were analyzed in relation to physicochemical and microbiological parameters. The AQRM was obtained through approaches in the stages of hazard identification, exposure assessment, dose-response assessment, and infection risk characterization. The results showed that the groundwater in the neighborhood does not conform the potability standards, mainly regarding the microbiological parameters, which in all samples presented values out of the limits established by the legislation. The MRQA showed high annual risk values, above the limit set by the U.S. Environmental Protection Agency (EPA) for exposures that occur with water intake. The study highlighted the urgency of establishing risk management actions for the water in the studied location. Additionally, awareness measures for the local population, through environmental education programs or projects, can be important for residents to understand the risks of consuming water from shallow wells without any treatment.

DOI: http:/dx.doi.org/10.14295/ras.v35i2.30043

\section{INTRODUÇÃO}

A qualidade da água destinada ao consumo humano tem sido alvo de pesquisas científicas, normas e legislações específicas, que orientam o uso de recursos hídricos para fins de potabilidade. Isso porque a escassez e a baixa qualidade dos recursos hídricos vêm aumentando em função de diversos fatores, como a poluição e contaminação das águas, o crescimento da demanda em algumas localizações em função de aglomerados urbanos e o desenvolvimento industrial e agrícola (RIBEIRO et al., 2019).
Segundo a Portaria de Consolidação n 5/2017 (BRASIL, 2017) do Ministério da Saúde, a água de consumo humano, destinada à ingestão, preparação e produção de alimentos e à higiene pessoal, independe da sua origem, desde que sejam atendidos os parâmetros físico-químicos e microbiológicos definidos por essa Portaria. Neste contexto, o uso da água subterrânea, captada em poços rasos, como fonte de abastecimento individual, apresenta-se como uma alternativa bastante adotada em todo o Brasil.

A prática de se utilizar poços rasos tem raízes históricas na 
humanidade, uma vez que grande parte dos seres humanos passou a buscar a água subterrânea como solução para as grandes distâncias entre os povoados e as fontes de água superficial. No entanto, Moreira e Pomini (2017) afirmam que atualmente, mesmo tendo acesso à água tratada, uma parte da população opta pela perfuração de poços, visando à economia financeira e à abundância de água.

Dentre os vários tipos de poços, os rasos, também chamados de cacimba ou poço amazonas, são, na maioria dos casos, empregados para abastecimentos individuais que requerem pequena vazão. São poços de grandes diâmetros (1 metro ou mais), escavados manualmente e revestidos com tijolos ou anéis de concreto. Possuem geralmente profundidades na ordem de até 20 metros (GIANPÁ; GONÇALES, 2005) e são construídos em terrenos facilmente desagregáveis, como aluviões ou mantos de alteração das rochas cristalinas. Em geral, isso é feito com o uso de equipamentos pequenos, tipo trados manuais ou mecanizados, ou pequenas sondas que usam jatos de água como elemento perfurador (HÉLLER; PÁDUA, 2006).

A captação em poços rasos, de acordo com Fenzl et al. (2018), explora os aquíferos próximos à superfície e, portanto, estes possuem maior probabilidade de contaminação por fontes antropogênicas, como fossas, cemitérios, postos de gasolina, depósitos de lixo, vazamentos de redes de esgoto, entre outros. Essas circunstâncias são mais preocupantes do ponto de vista de saúde pública, posto que muitas vezes as populações consomem a água subterrânea sem tratamento prévio.

Nesse âmbito, Capp et al. (2012) constataram, em um estudo realizado na área urbana de Anastácio (MS), que 58,3\% dos consumidores de água subterrânea obtida por poços rasos apresentaram a opinião de que a água possuía ótima qualidade, tendo como parâmetros a aparência limpa e ausência de sabor da água. Com isso, concluíram que essa circunstância impede que os consumidores tratem essa água pelo menos por um processo de desinfecção, o que certamente minimizaria o risco de veiculação de enfermidades.

No município de Colinas (RS), análises físico-químicas e microbiológicas realizadas em 12 poços rasos constataram contaminação microbiológica em todos os pontos amostrados, e somente cinco de um total de 12 amostras estavam em conformidade com a até então vigente Portaria $n^{\circ} 2.914 / 2011$ do Ministério da Saúde (SALING et al., 2017). Souza et al. (2018) identificaram, na área urbana da cidade de Astolfo Dutra (MG), dentre amostras de água coletadas em 23 pontos, que em 13 destas havia a presença de coliformes totais, e uma apresentou contaminação por coliformes termotolerantes. Ainda, de acordo com os autores, apenas cinco do total das amostras analisadas atenderam aos parâmetros de potabilidade de água. Tais resultados evidenciam o risco de contaminação das águas subterrâneas em grandes metrópoles com abundantes fontes de contaminação, como é o caso do município de Goiânia.

A contaminação da água ocorre pela presença de substâncias tóxicas, radioativas ou organismos patogênicos, em quantida des prejudiciais à saúde humana. A contaminação por organismos patogênicos na água pode desencadear a transmissão de doenças infecciosas como cólera, legionelose, febre, tifoide e gastroenterites (MADIGAN et al., 2016). Como exemplo, no estudo de Usman et al. (2018), realizaram-se testes microbiológicos em amostras de água armazenadas em casa, provenientes de poços, nascentes, rios, entre outros, a nível doméstico e comunitário, de uma comunidade rural da Etiópia. Constatou-se que a desinfecção da água para consumo doméstico e o descarte seguro de fezes de crianças diminuíram a incidência de diarreia infantil em $16 \%$ e 23\%, respectivamente.

Além da avaliação da qualidade da água, a mensuração do risco de infecção pela exposição a patógenos presentes é uma opção para o controle dos efeitos adversos que a contaminação pode causar. Para a determinação de riscos à saúde humana, existem atualmente diferentes metodologias de avaliação de risco.

A avaliação de risco é um mecanismo que possibilita a definição de medidas de intervenção, controle e análise dos impactos aos riscos associados a uma determinada atividade. Em se tratando de riscos microbiológicos, a Avaliação Quantitativa de Risco Microbiológico (AQRM), ferramenta empregada neste estudo, oferece a definição do risco de infecção envolvendo a exposição a patógenos.

Para a Organização Mundial da Saúde (WHO, 2016), a AQRM é uma estrutura ou um mecanismo que permite que dados científicos quantitativos sejam interpretados no contexto dos resultados estimados de saúde, a fim de apoiar a gestão da segurança hídrica. Na pesquisa de Machdar et al. (2013), aplicou-se a AQRM utilizando-se uma razão entre Escherichia coli e organismos patogênicos. Assim, concluiu-se que o risco de infecção por bactérias, vírus e helmintos patogênicos excedeu o valor de referência da Organização Mundial da Saúde (WHO, 2001). Por conseguinte, com base nos resultados, foram propostos sistemas de intervenção econômicos que reduziriam em $46 \%$ o risco de infecção.

O presente estudo partiu da preocupação com a saúde de uma população que utiliza água subterrânea para consumo, em um bairro da Região Sudoeste do município de Goiânia. Desse modo, este estudo se justifica pela relação entre a análise da água, a segurança hídrica e a prevenção de doenças relacionadas à água contaminada. 0 objetivo foi avaliar a qualidade da água e empregar a AQRM como uma ferramenta para a definição do risco de infecção associado à exposição a patógenos emergentes na água subterrânea de um bairro da Região Sudoeste de Goiânia.

\section{MATERIAIS E MÉTODOS}

\section{1. Área de estudo}

A área de estudo localiza-se na Região Sudoeste do município de Goiânia, próximo à divisa intermunicipal com Aparecida de Goiânia, a cerca de 16 quilômetros de distância da região central do município. 0 bairro abrange uma área de 509.210,356 
Figura 1 - Localização da área de estudo na Região Sudoeste de Goiânia

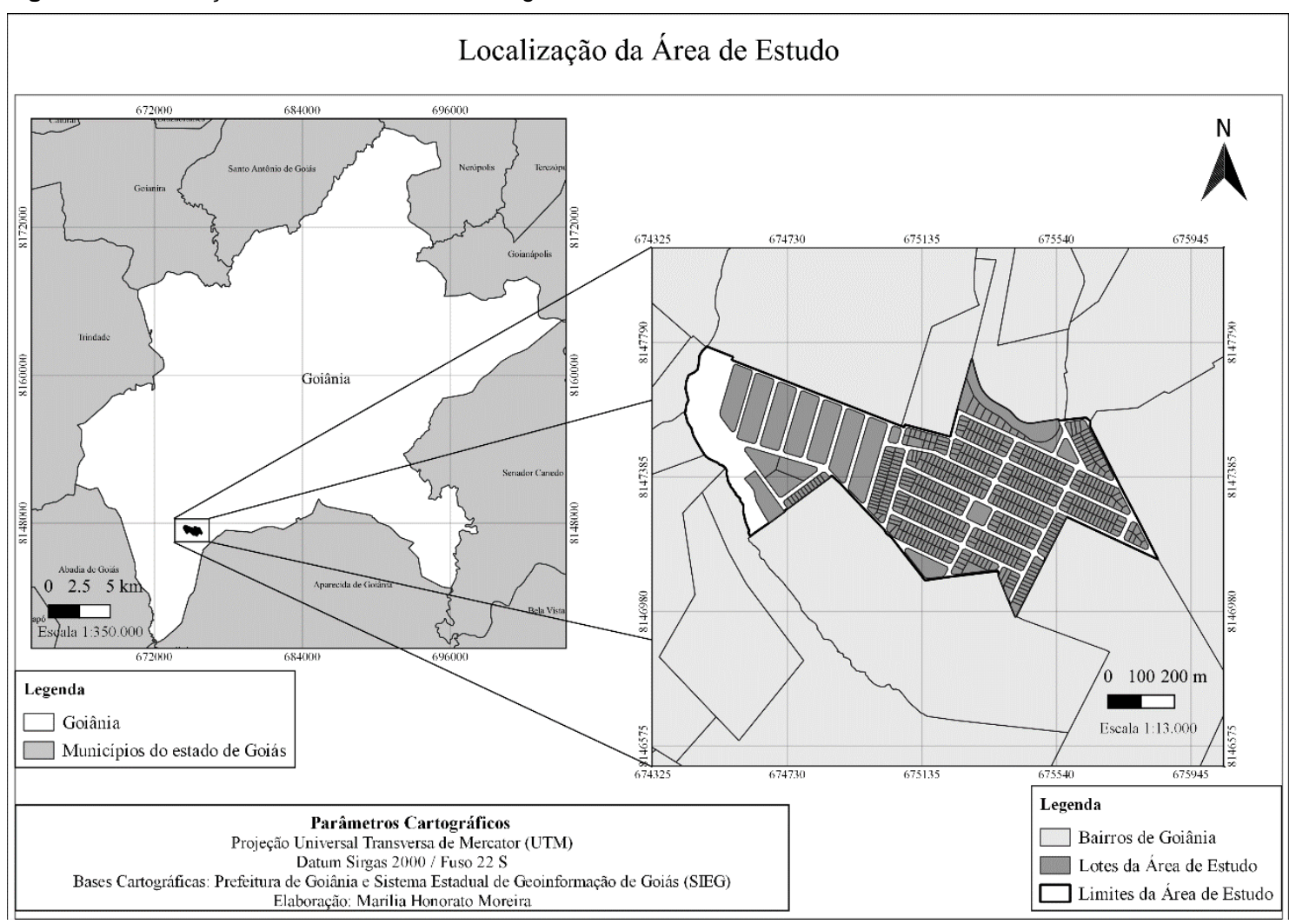

O bairro estudado é constituído por 32 quadras e 554 lotes, sendo predominantemente residencial e composto por, além de residências, alguns comércios familiares e áreas públicas como escolas e praças. Conforme dados da Prefeitura Municipal de Goiânia (GOIÂNIA, 2013), no ano de 2013, residiam no bairro um total de 1.735 habitantes.

$\mathrm{Na}$ localidade existe rede abastecimento de água, contudo, cerca de $28,7 \%$ das residências ainda utilizam integral ou parcialmente a água subterrânea por meio de poços rasos para consumo. 0 esgoto gerado nas residências é destinado às fossas negras, uma vez que não há rede de coleta de esgoto na área.

\subsection{Coleta de amostras}

A partir dos dados georreferenciados da localização do bairro e dos boletins de informações cadastrais dos lotes, disponibilizados pela Prefeitura Municipal de Goiânia (GOIÂNIA, 2019), foi possível associar e mapear, para cada lote, as características pertinentes quanto ao abastecimento de água e à desti- nação do esgoto sanitário. Assim, foram selecionados 30 pontos de coleta (Figura 2), que possuíam cacimbas como fonte de abastecimento de água, e onde o esgoto sanitário era destinado para a fossa negra.

No que se refere à quantidade de amostras, foi coletada uma amostra de água por ponto de coleta para cada parâmetro analisado em laboratório. 0 aferimento dos parâmetros medidos em campo foi realizado em triplicata em cada ponto de coleta.

A coleta e preservação das amostras seguiram as especificações da Companhia Ambiental do Estado de São Paulo (CETESB, 2011), respeitando-se as normas de temperatura, acondicionamento e de tempo máximo de validade das amostras para cada tipo de análise. Para tanto, aplicaram-se os procedimentos de planejamento de amostragem, organização dos trabalhos de campo, controle de qualidade na amostragem, equipamento de amostragem e ensaios de campo. 


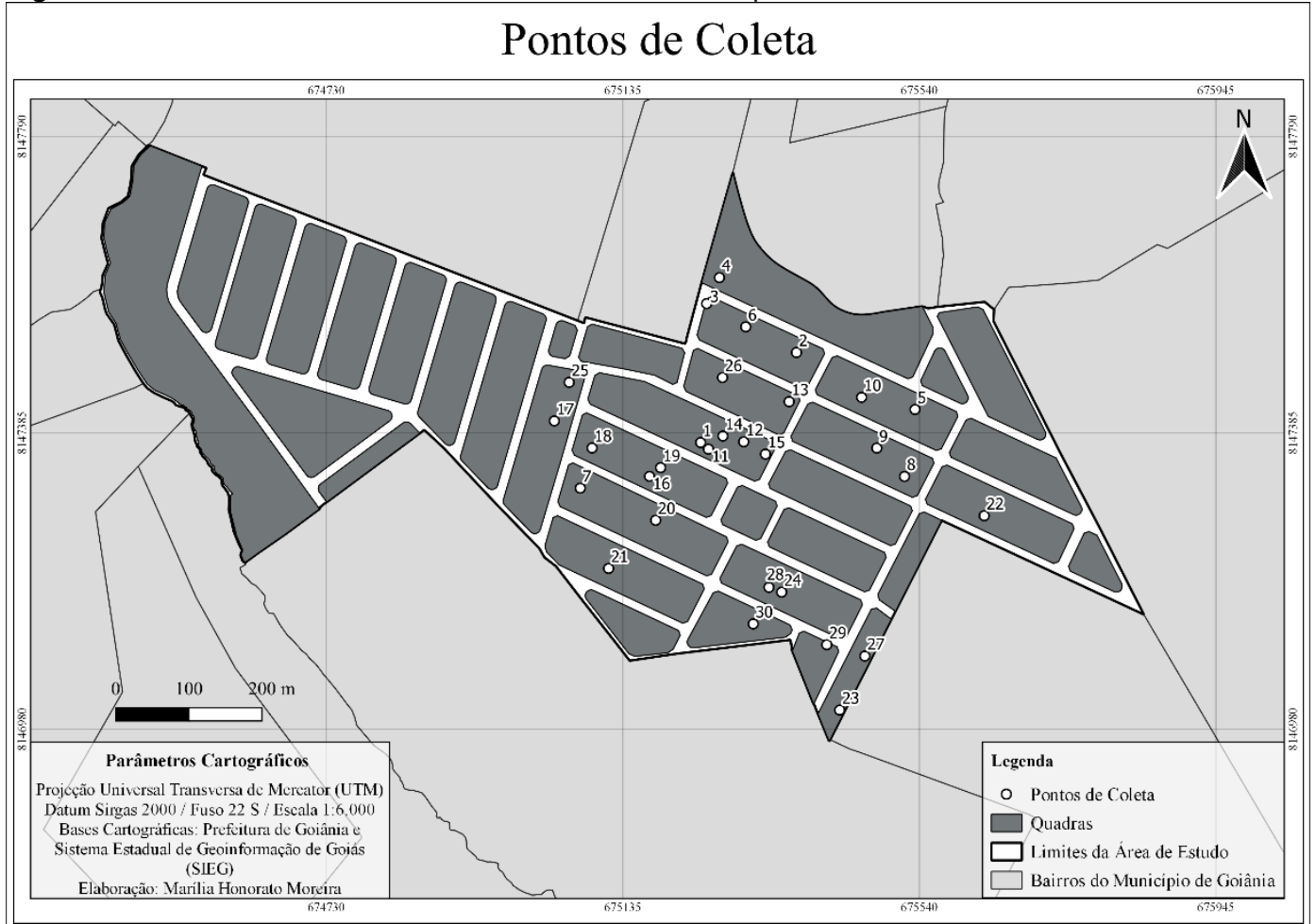

As coletas foram realizadas durante três semanas, sendo duas consecutivas e uma após um intervalo de uma semana, entre os meses de outubro e novembro de 2019. Ocorreram alguns episódios de chuva durante a segunda e a terceira semanas de coleta. No entanto, como todos os poços têm tampa e são usados para abastecimento de água subterrânea, acredita-se que a pluviosidade não tenha tido interferência direta e imediata sobre a água coletada.

Para a organização das informações levantadas em campo, foi utilizado um checklist contendo questões sobre o local da coleta, o horário da coleta, a localização das cacimbas e das fossas, os focos de contaminação e as observações pertinentes.

\subsection{Qualidade da água}

$\mathrm{Na}$ avaliação da qualidade da água foram considerados os parâmetros físico-químicos e microbiológicos, sendo: turbidez, alcalinidade, dureza, pH, cor aparente, cor verdadeira, oxigênio dissolvido, temperatura, nitrogênio total, nitrogênio amoniacal, coliformes totais e Escherichia coli (E. coli).

As análises físico-químicas dos parâmetros turbidez, alcalinidade, dureza, cor aparente e cor verdadeira foram realizadas com base no manual de procedimentos do Standard Methods (APHA, 2017). Para os parâmetros nitrogênio total e nitrogênio amoniacal, as análises foram realizadas conforme o Manual de Análises Físico-Químicas de Águas de Abastecimento e Residuárias (SILVA; OLIVEIRA, 2001). Os resultados de pH, oxigênio dissolvido e temperatura foram obtidos em campo, por meio da utilização das sondas do medidor digital multiparâme- tros HQ40D da Hach. Este foi calibrado antes de cada coleta por um técnico especializado e seguiu as especificações de calibração do fabricante.

Para os parâmetros microbiológicos, empregou-se o ensaio cromogênico com utilização do kit Colilert (IDEXX), conforme o Standard Methods 9223 (APHA, 2017), para terminação de coliformes por substratos enzimáticos. Para a quantificação da concentração de E. coli por $100 \mathrm{~mL}$ de amostra, empregouse a tabela IDEXX Quanti-Tray/2000 para o Número Mais Provável (NMP) por $100 \mathrm{~mL}$. Todas as análises microbiológicas foram realizadas em laboratório com sala própria e exclusiva para esse tipo de análise (https://lana.eec.ufg.br/p/19366laboratorio-de-microbiologia) e tiveram a supervisão de um técnico especializado.

$\mathrm{Na}$ avaliação dos resultados obtidos, consideraram-se a qualidade da água para consumo humano e seu padrão de potabilidade, segundo definido no Anexo XX da Portaria de Consolidação $n^{\circ}$ 5/2017 do Ministério da Saúde (BRASIL, 2017). Os parâmetros que não constam na Portaria (alcalinidade, oxigênio dissolvido, cor verdadeira e temperatura) foram discutidos de acordo com as revisões da literatura.

\subsection{Avaliação quantitativa de risco microbiológico}

Com base na estrutura metodológica, foram abordadas quatro etapas: identificação do perigo (definição dos patógenos preocupantes); avaliação da exposição; avaliação dose-resposta e caracterização do risco de infecção (HAAS et al., 1999). 


\subsubsection{Identificação do perigo}

Foram considerados, neste estudo, três patógenos de referência: Giardia, Cryptosporidium e Campylobacter.

A Giardia e o Cryptosporidium são protozoários oportunistas responsáveis por doenças de veiculação hídrica e se apresentam como problemas de saúde pública. Esses patógenos são agentes que apresentam (oo)cistos resistentes ao tratamento convencional de água e se caracterizam por causar sérias morbidades em indivíduos imunocomprometidos (FREGONESI et al., 2012).

Embora a literatura científica brasileira ainda disponha de poucas informações sobre surtos de Criptosporidiose, o estudo de revisão de Bataiero (2016) traz informações importantes sobre o tema. De acordo com o autor, uma pesquisa realizada em San Antonio, Texas (EUA), em 1984, documentou um surto de Criptosporidiose que afetou cerca de 2.000 pessoas que consumiram água de poço contaminada por esgoto. Em 1998, também no Texas, cerca de 1.400 pessoas foram diagnosticadas com Criptosporidiose devido ao vazamento de esgoto na água subterrânea utilizada para o abastecimento público.

Quanto à presença de Giardia e Cryptosporidium em águas subterrâneas, a investigação realizada por Mastropaulo e Razzolini (2018) em poços de São Paulo, onde ocorre a captação de água para consumo humano, detectou a presença de (oo)cistos de Cryptosporidium ou de Giardia em 53\% das amostras analisadas.
A bactéria patogênica Campylobacter também está relacionada a surtos de doenças de veiculação hídrica. Segundo Chukwu et al. (2019), vários estudos avaliaram a prevalência de Campylobacter spp em diferentes fontes de água. Na África do Sul, foi identificada em $13 \%$ de amostras de águas superficiais e subterrâneas, e, na Nova Zelândia, em 75\% de amostras em águas subterrâneas. Ainda, as contribuições da água para a carga de casos esporádicos de infecções por Campylobacter podem ser desconhecidas, porque nem todos os casos levam a doenças graves e, na maioria das vezes, um grau mais brando de uma doença pode não exigir atenção médica.

A Portaria de Consolidação n ${ }^{\circ}$ 5/2017 do Ministério da Saúde (BRASIL, 2017) recomenda a avaliação da presença de cistos de Giardia spp. e oocistos de Cryptosporidium spp. em água destinada ao consumo humano, quando for identificada média geométrica anual maior ou igual a 1.000 Escherichia coli/100mL.

\subsubsection{Avaliação da exposição}

Para a estimativa da concentração dos patógenos na água de consumo, foram utilizadas razões entre a proporção de patógenos e E. coli, propostas por Eregno et al. (2016). Para os autores, as relações foram definidas com base em estudos anteriores e consideraram o contexto das principais fontes de contaminação microbiana das águas para os sistemas de tratamento de esgoto norueguês. Na Tabela 1 são apresentadas as relações entre $E$. coli e os patógenos de referência.

Tabela 1 - Valores da literatura quanto à concentração média de patógenos e a proporção patógeno: E. coli foi usada como entrada para o modelo

\begin{tabular}{cccc}
\hline $\begin{array}{c}\text { Patógenos e indicador } \\
\text { patogênico por } 100 \mathrm{ml}\end{array}$ & $\begin{array}{c}\text { Concentração } \\
\text { Média }\end{array}$ & Referências & $\begin{array}{c}\text { Razão } \\
\text { patógeno: E. Coli }\end{array}$ \\
\hline E. coli & $5,9 \times 10^{6}$ & Grøndahl-Rosado et al. (2014) & $1: 1$ \\
Giardia & 759,5 & Robertson et al. (2006) & $1,3 \times 10^{-4}$ \\
Cryptosporidium & 678,1 & Robertson et al. (2006) & $1,2 \times 10^{-4}$ \\
Campylobacter & - & Estimado no estudo & $2,0 \times 10^{-5}$ \\
\hline
\end{tabular}

Fonte: Eregno et al. (2016).

Para a concentração de E. coli e dos patógenos de referência foram calculados a média e o percentil 95\%, aproximado pela distribuição Gamma UCL. Os valores médios e o percentil 95\% da taxa de ingestão diária de água foram obtidos de U.S. EPA (2019) em mL/kg.dia. A fim de adaptar melhor estes dados à realidade do estudo, os valores foram multiplicados pelo peso corpóreo da população brasileira, obtidos de IBGE (2010). Deste modo, obtiveram-se o valor da taxa de ingestão médio e o percentil de $95 \mathrm{em} \mathrm{ml}$ /dia. Foram considerados dois grupos da população: crianças menores de 5 anos e adultos maiores de 20 anos, por serem os grupos mais vulneráveis ao desenvolvimento de formas graves de doenças diarreicas.

\subsubsection{Avaliação dose-resposta}

A análise da dose-resposta visa à caracterização matemática da relação entre a dose administrada e a probabilidade de infecção ou doença na população exposta ao patógeno de interesse (HAAS et al., 1999). Neste estudo, os modelos dose-resposta utilizados foram os modelos Exponencial e Beta-Poisson. Os parâmetros considerados seguiram o disposto por Eregno et al. (2016), por se tratarem dos valores mais adequados encontrados na literatura frente aos patógenos de referência escolhidos e o contexto considerado para o estudo. Na Tabela 2 são apresentados os parâmetros dose-resposta considerados no estudo. 
Tabela 2 - Parâmetros dose-resposta para cada patógeno utilizado na avaliação de riscos

\begin{tabular}{cccc}
\hline Patógenos & Modelos & Parâmetros & Referências \\
\hline Giardia & Exponencial & $r=0,0199$ & Haas et al. (1999) \\
Cryptosporidium & Exponencial & $r=0,2$ & WHO (2011) \\
Campylobacter & Beta-Poisson & $\alpha=0,15, \beta=7,9$ & Teunis et al. (1999) \\
\hline
\end{tabular}

Fonte: Eregno et al. (2016).

\subsubsection{Caracterização do risco de infecção}

Segundo Haas et al. (1999), os modelos dose-resposta são dados por meio das Equações 1 e 2, dispostas a seguir:

- Modelo Exponencial

$$
P i=1-e^{-r d}
$$

Em que:

$\mathrm{Pi}=$ probabilidade de infecção para um grupo de pessoas que recebeu uma dose média $d$;

$r$ = parâmetro característico da relação patógeno-hospedeiro; $\mathbf{d}=$ dose que é dada pelo produto da concentração de patógeno na água pela taxa de ingestão diária.

\section{- Modelo Beta-Poisson}

$$
P i=1-(1+d / \beta)^{-\alpha}
$$

Em que:

$\mathrm{Pi}$ = probabilidade diária de infecção;

$\beta, \alpha=$ parâmetros característicos da relação patógeno-hospedeiro;

d = dose que é dada pelo produto da concentração de patógeno na água pela taxa de ingestão diária.

O risco anual (Equação 3) é calculado por:

$P_{a}=1-\left(1-P_{1}\right) 365$
Em que:

$\mathrm{P}_{\mathrm{a}}=$ probabilidade de infecção anual;

$P_{I}=$ probabilidade de infecção diária.

\section{RESULTADOS E DISCUSSÃO}

\subsection{Qualidade da água}

A Portaria de Consolidação n 5/2017 (BRASIL, 2017) do Ministério da Saúde estabelece, em seu artigo $5^{\circ}$, que a água para consumo humano é definida como a água potável destinada à ingestão, preparação e produção de alimentos e à higiene pessoal, independentemente da sua origem (BRASIL, 2017). Desta forma, define-se, em seu Anexo XX, o conjunto de valores permitidos como parâmetro da qualidade da água para consumo humano, estabelecendo um padrão de potabilidade. Os resultados deste estudo foram analisados com base nas diretrizes dessa Portaria.

Os resultados das análises microbiológicas das amostras mostram que nenhum dos pontos atendeu aos padrões de potabilidade, uma vez que apresentaram contaminação por coliformes totais e por E. coli acima dos Valores Máximos Permitidos (VMP) pela Portaria de Consolidação $n^{\circ} 5 / 2017$, conforme pode ser observado na Figura 3. Neste contexto, a situação observada torna a água inadequada para o consumo humano em virtude do risco de doenças de veiculação hídrica.

Figura 3 - Valores dos parâmetros microbiológicos em contraste com os VMP

\section{Parâmetros Microbiológicos}

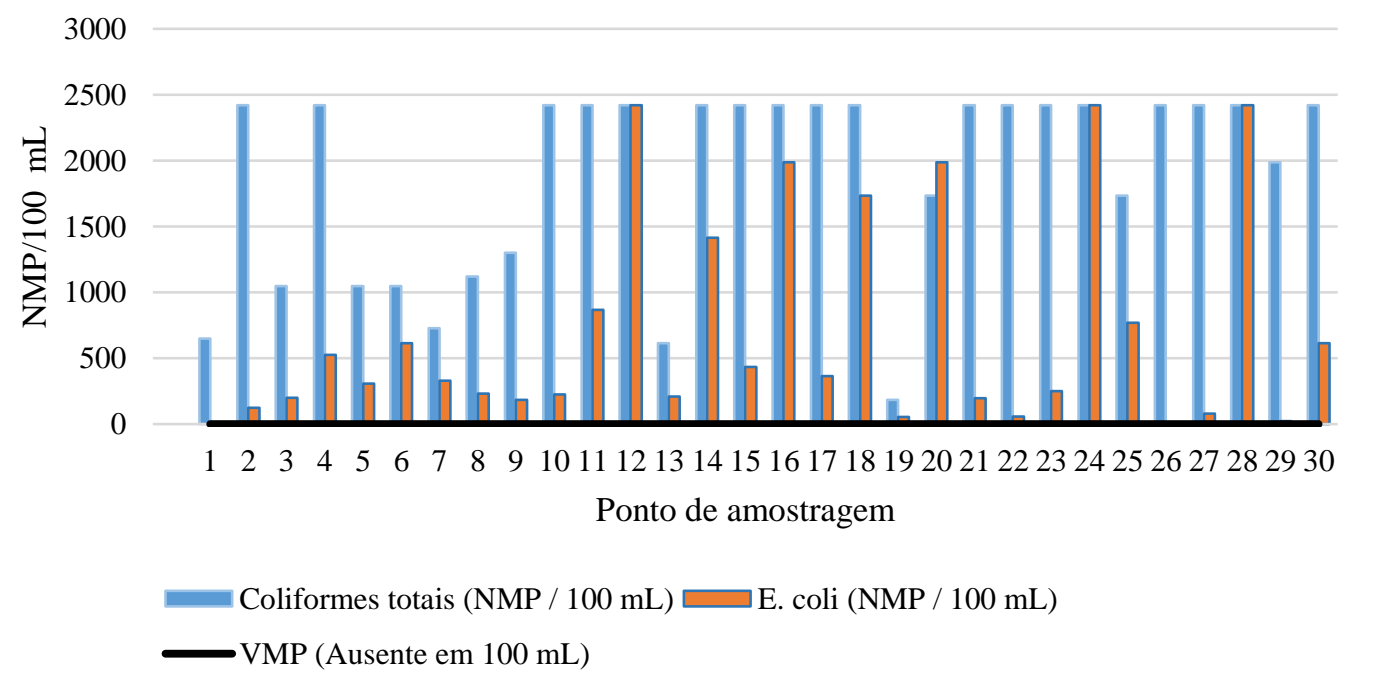

Fonte: os autores (2020). 
A maioria dos valores de turbidez foi inferior aos limites definidos pela Portaria, sendo que apenas uma amostra apresentou valor superior. Uma vez que a turbidez é definida como a medida da dificuldade de um feixe de luz atravessar uma certa quantidade de água e é causada por matérias sólidas em suspensão (silte, argila, coloides, matéria orgânica etc.), as águas subterrâneas normalmente não apresentam turbidez elevada. A Figura 4 apresenta os resultados de turbidez obtidos.

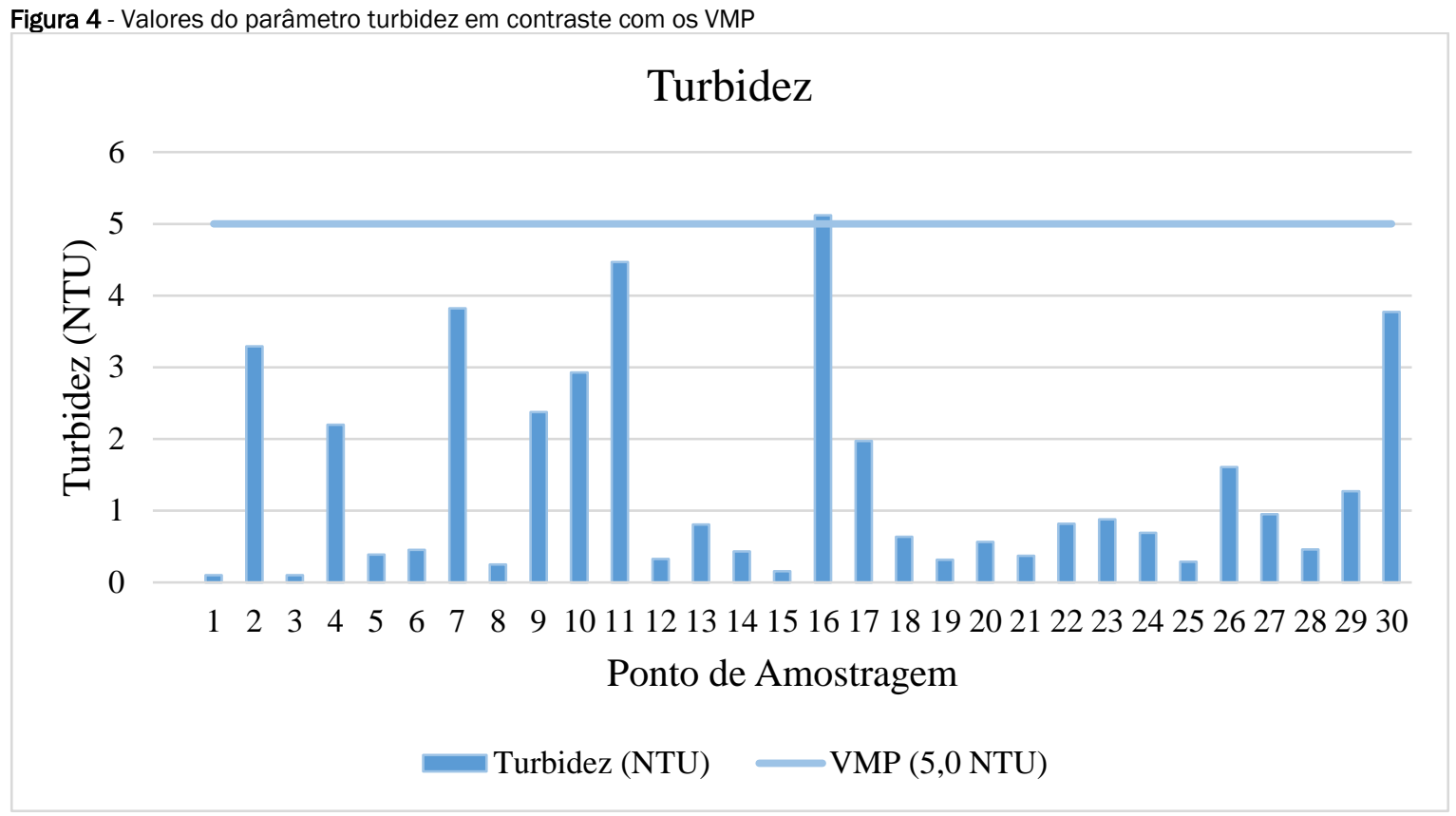

Fonte: os autores (2020)

Todos os valores de dureza foram significativamente inferiores ao valor máximo permitido de 5,0 NTU. A Portaria de Consolidação $n^{\circ} 5 / 2017$ define que os valores de $\mathrm{pH}$ devem compreender o intervalo de 6,0 a 9,5. Conforme observado na Figura $5,33,3 \%$ das amostras coletadas apresentaram valores de $\mathrm{pH}$ inferiores ao limite mínimo, o que indica acidez na água. Além disso, sete amostras apresentaram valores de cor verdadeira acima do valor máximo estipulado pela legislação vigente ( $\mathrm{Fi}-$ gura 6).

Figura 5 - Valores do parâmetro pH em contraste com o intervalo de VMP estipulado

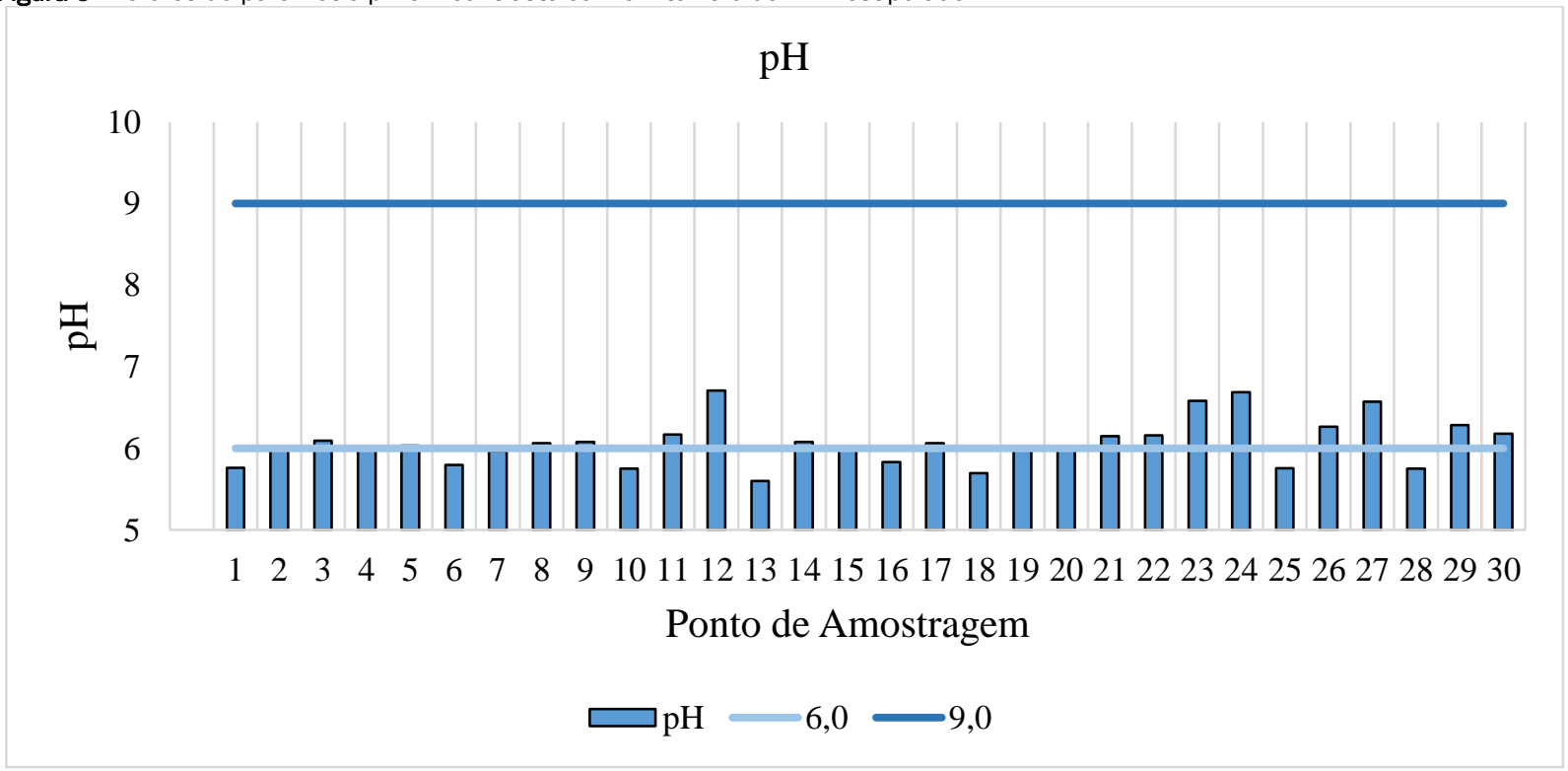

Fonte: os autores (2020). 
Figura 6 - Valores de cor aparente com o intervalo de VMP

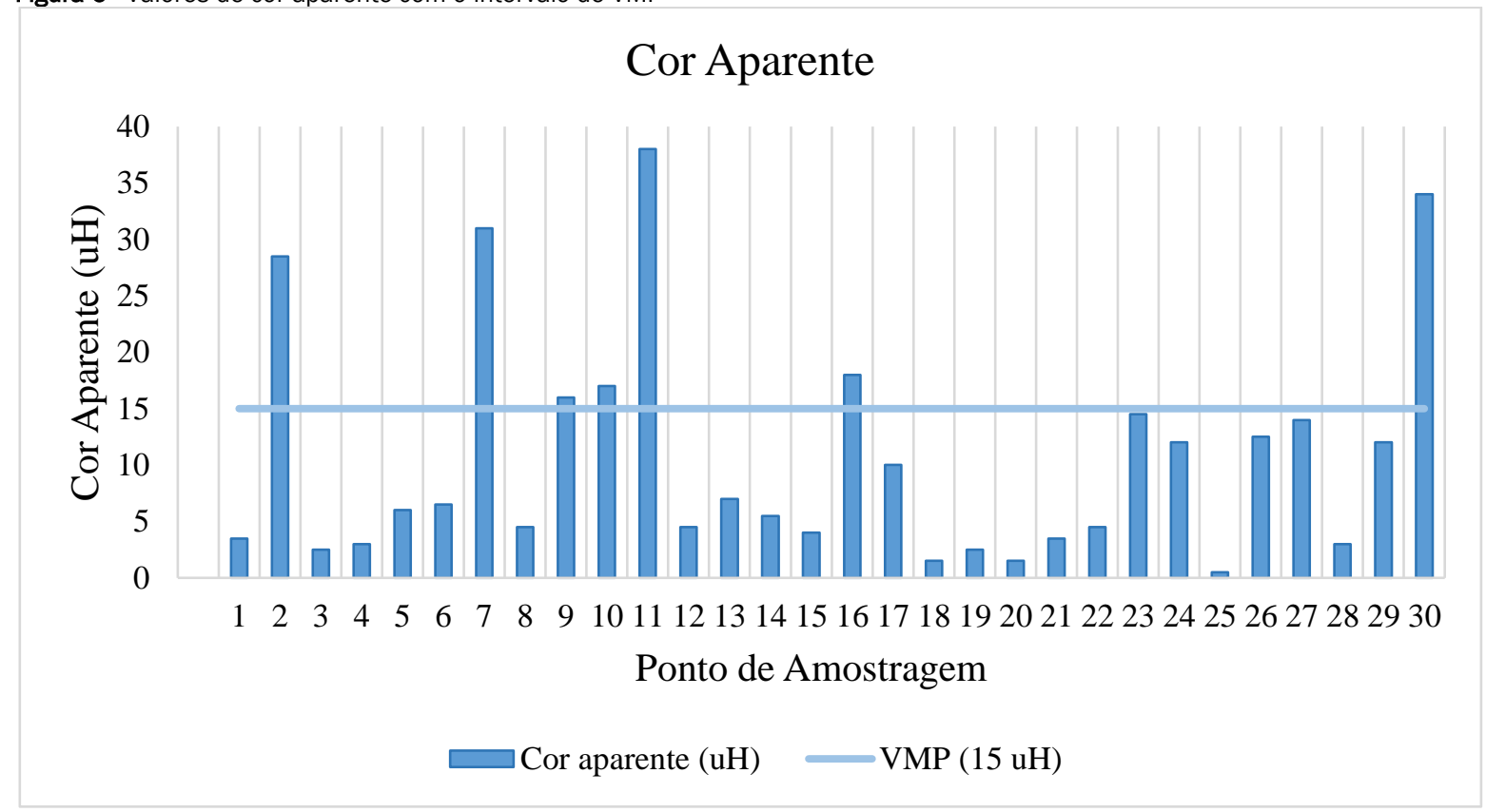

Fonte: os autores (2020).

Os parâmetros de alcalinidade, oxigênio dissolvido, cor verdadeira e temperatura não possuem valores máximos permitidos definidos pela Portaria. Contudo, apesar de não serem inseridos como padrões para potabilidade, tais parâmetros podem ser considerados principalmente frente à possibilidade de oferecerem riscos à saúde.

A alcalinidade é um parâmetro importante a ser considerado pelo caráter corrosivo ou incrustante que apresenta, bem como pelo fato de que pode afetar o sabor da água em altas quantidades. A maioria das águas naturais apresenta valores

de alcalinidade na faixa de 30 a 500 mg/L em $\mathrm{CaCO}_{3}$ (BRASIL,
2014). Os valores de alcalinidade encontrados na área de estudo foram no máximo $38,5 \mathrm{mg} / \mathrm{L}$ em $\mathrm{CaCO}_{3}$ e no mínimo de $7,5 \mathrm{mg} / \mathrm{L}$ em $\mathrm{CaCO}_{3}$, o que é relativamente baixo e pode indicar uma baixa capacidade da água de neutralizar ácidos.

A cor verdadeira é a cor medida em amostras sem turbidez. É um parâmetro estético que pode influenciar a aceitação da água e indica substâncias absorvidas nesta (BRASIL, 2014). Destarte, os valores obtidos (Figura 7) exprimem a possibilidade da presença de uma quantidade considerável de substâncias absorvidas.

Figura 7 - Valores do parâmetro cor verdadeira

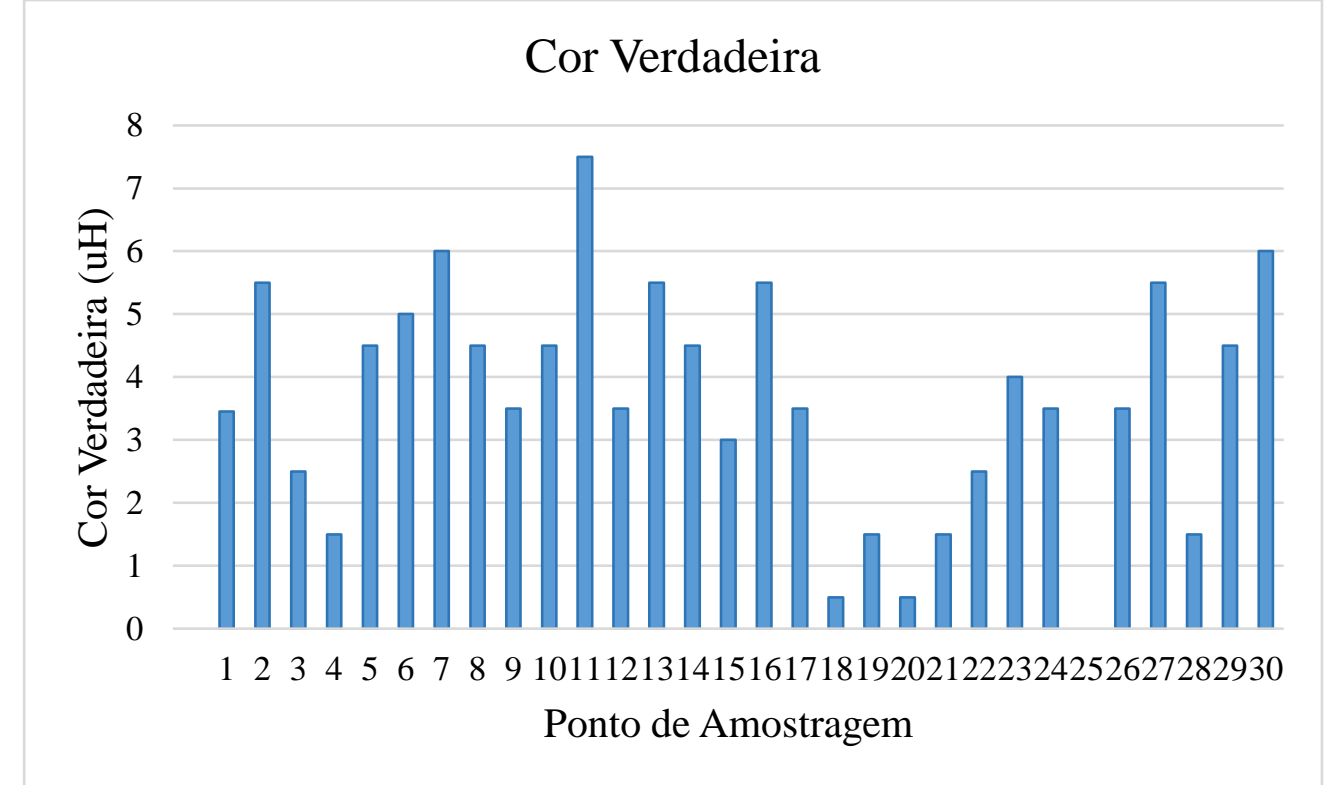

Fonte: os autores (2020). 
Os valores de oxigênio dissolvido (Figura 8) foram medidos em campo na água bombeada dos poços rasos e, logo, houve aeração das amostras. No entanto, mesmo com esse viés de amostragem, os valores encontrados foram considerados válidos, pois se considerou a água dentro das características em que são consumidas pela população local. De tal modo, os re sultados desse parâmetro indicam a boa capacidade da água subterrânea local em solubilizar esse gás.

Os valores de temperatura levantados, dispostos na Figura 9, estavam condizentes com as temperaturas ambientes nos momentos das coletas.

Figura 8 - Valores do parâmetro oxigênio dissolvido

\section{Oxigênio Dissolvido}

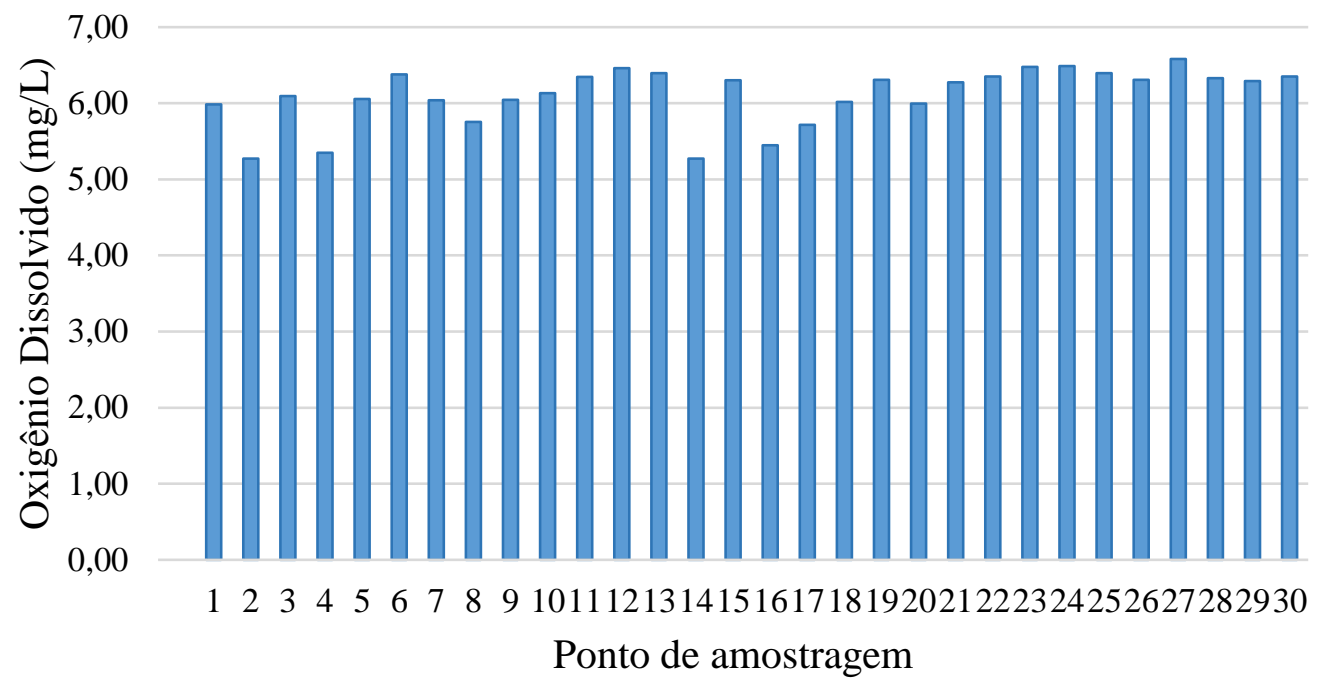

Fonte: os autores (2020)

Figura 9 - Valores do parâmetro temperatura

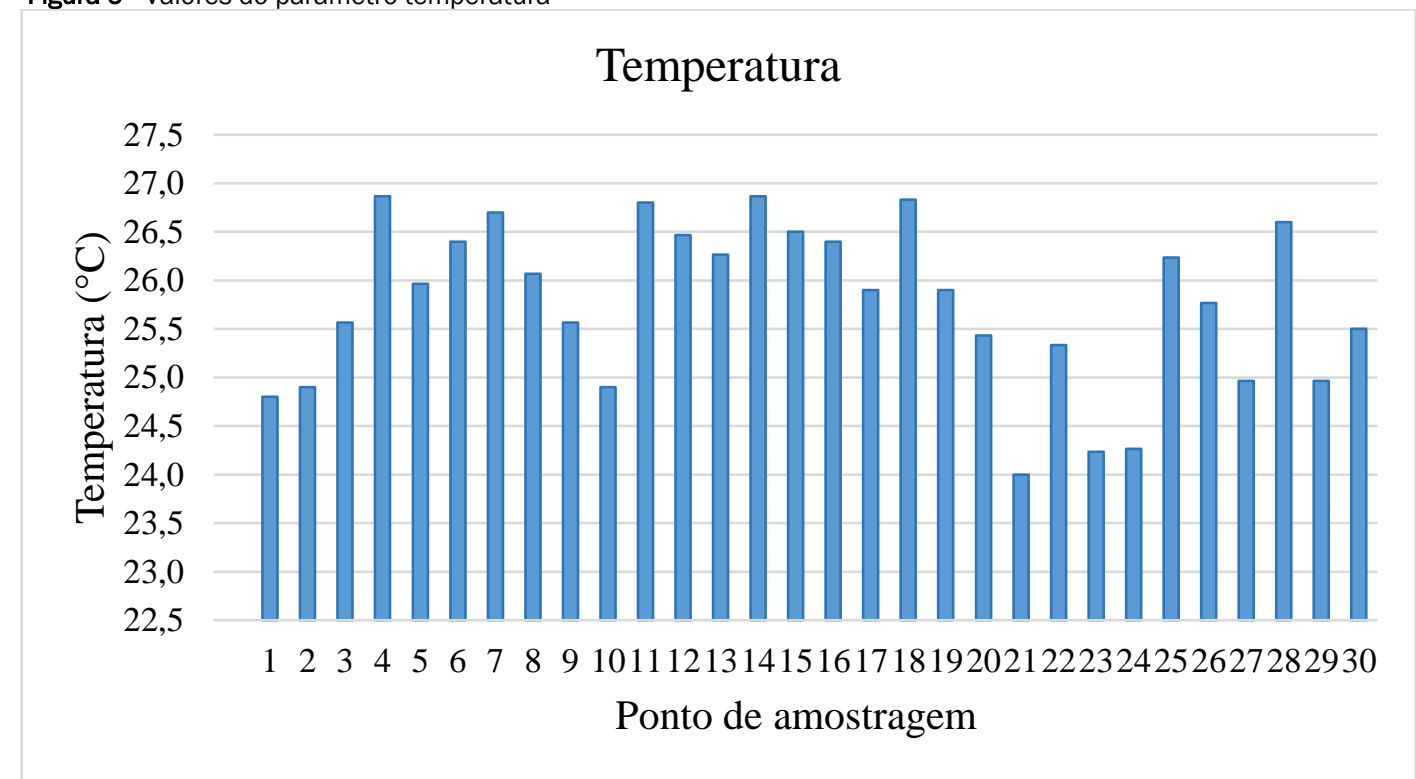

Fonte: os autores (2020).

Sobre as análises de nitrogênio, cinco amostras apresentaram valores superiores ao limite de 1,25 mg N/L. Além disso, 17 amostras têm valores superiores à média característica de $0,26 \mathrm{mg} \mathrm{N} / \mathrm{L}$ de nitrogênio total. Esses resultados são expressos na Figura 10. Deste modo, tais informações, associadas às altas concentrações de contaminação microbiológica analisadas, podem indicar contaminação por fontes de poluição próximas, o que pode estar relacionado à presença das fossas negras ou a outras fontes de poluição.

Para Barros (2004), a presença de nitrogênio em uma amostra de água pode indicar poluição orgânica. Quanto ao nitrogênio amoniacal, segundo Alaburda e Nishihara (1998), a amônia pode estar presente naturalmente em águas superficiais 
ou subterrâneas, em baixas concentrações. Contudo, a ocorrência de concentrações elevadas pode ser resultante de fontes de poluição próximas, bem como da redução de nitrato por bactérias ou por íons ferrosos presentes no solo.

Estudos adicionais, na mesma área deste estudo, podem considerar a proximidade das fossas negras em relação aos poços rasos, bem como a direção da sua pluma de contaminação, o que não foi realizado neste estudo.
No estado de São Paulo, um estudo que visou a estabelecer valores de referência de qualidade das águas subterrâneas de sete aquíferos apresentou 1,25 mg/L de N como VMP para a concentração de nitrogênio amoniacal na água. Além disso, o mesmo estudo determinou 0,26 mg N/L como uma média de concentrações características dos aquíferos estudados (CETESB, 2016). Para o estado de Goiás, não existem valores de referência.

Figura 10 - Valores dos parâmetros nitrogênio total e nitrogênio amoniacal

\section{Nitrogênio Total e Amoniacal}

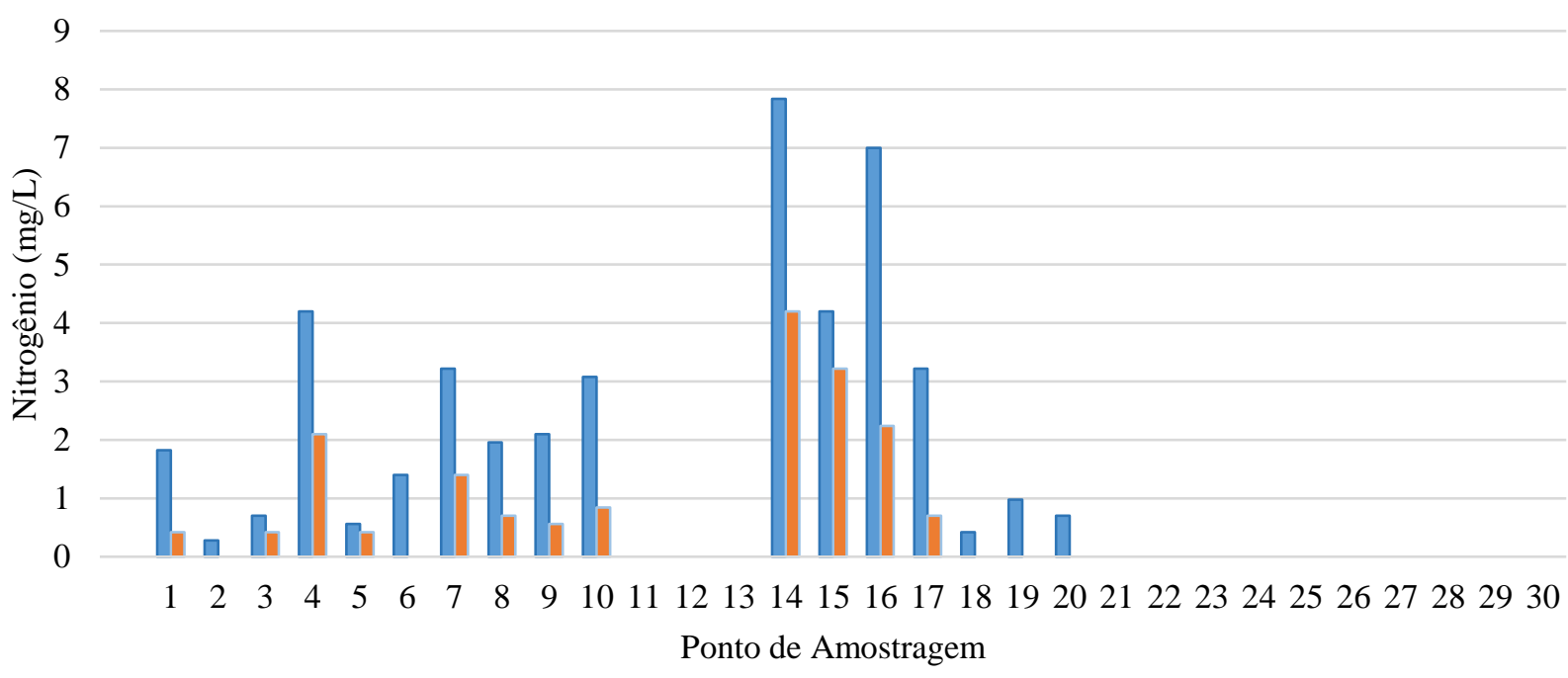

$\square$ Nitrogênio Total (mg/L) $\quad$ Nitrogênio amoniacal (mg/L)

Fonte: os autores (2020).

No que diz respeito às informações sobre focos de contaminação, foi observada a presença de animais de estimação e da disposição de materiais de construção no solo na maioria dos pontos. Em seis locais, observou-se a disposição de resíduos sólidos no solo; contudo, os resultados correspondentes a essas situações não se destacaram. Alguns, inclusive, se apresentaram inferiores aos de locais onde não ocorre essa prática. 0 principal foco de contaminação, comum a todas as residências, são as fossas negras.

Os resultados das análises de qualidade da água demonstram que a água subterrânea do bairro não se encontra em um padrão de potabilidade adequado, em especial, considerando-se os parâmetros microbiológicos que apresentaram resultados elevados. Os valores de turbidez, cor aparente e nitrogênio tiveram resultados condizentes com a situação microbiológica, o que pode indicar a contaminação da água por situações externas e uma grande carga de decomposição de matéria orgânica no aquífero livre de onde é captada a água.

\subsection{Avaliação quantitativa de risco microbiológico}

\subsubsection{Probabilidade de infecção}

A presença de $E$. coli foi detectada em $100 \%$ das amostras dos pontos de captação de água subterrânea, com concentrações variando de 1 a mais de 2.419,6 NMP/100 mL. Para a estimativa das concentrações de patógenos na água de consumo, aplicaram-se as razões patógenos/E. coli da Tabela 1 para: Giardia, Cryptosporidium e Campylobacter. Os valores de riscos diário e anual (média e percentil de 95\%) são apresentados nas Tabelas 3 e 4, respectivamente, para crianças menores de 5 anos e adultos maiores de 20 anos.

Tabela 3 - Risco diário de infecção

\begin{tabular}{ccccccc}
\hline \multirow{2}{*}{ Grupo } & \multicolumn{2}{c}{ Giardia } & \multicolumn{2}{c}{ Cryptosporidium } & \multicolumn{2}{c}{ Campylobacter } \\
& Média & Percentil 95 & Média & Percentil 95 & Média & Percentil 95 \\
& & & & & \\
Crianças & $6,7 \times 10^{-3}$ & $4,8 \times 10^{-2}$ & $6,1 \times 10^{-2}$ & $3,7 \times 10^{-1}$ & $9,9 \times 10^{-4}$ & $7,0 \times 10^{-3}$ \\
Adultos & $1,3 \times 10^{-2}$ & $6,4 \times 10^{-2}$ & $1,2 \times 10^{-1}$ & $4,6 \times 10^{-1}$ & $2,0 \times 10^{-3}$ & $9,4 \times 10^{-3}$ \\
\hline
\end{tabular}


Tabela 4 - Risco anual de infecção

\begin{tabular}{ccccccc}
\hline \multirow{2}{*}{ Grupo } & \multicolumn{2}{c}{ Giardia } & \multicolumn{2}{c}{ Cryptosporidium } & \multicolumn{2}{c}{ Campylobacter } \\
& Média & Percentil 95 & Média & Percentil 95 & Média & Percentil 95 \\
\hline Crianças & $9,1 \times 10^{-1}$ & 1,0 & 1,0 & 1,0 & $3,0 \times 10^{-1}$ & $9,2 \times 10^{-1}$ \\
Adultos & $9,9 \times 10^{-1}$ & 1,0 & 1,0 & 1,0 & $5,1 \times 10^{-1}$ & $9,7 \times 10^{-1}$ \\
\hline
\end{tabular}

Os resultados mostram valores de risco anual elevados para crianças e adultos para os três patógenos estudados. 0 risco de infecção por Cryptosporidium foi maior dentre os patógenos estudados, seguido pelo risco de infecção por Giardia e Campylobacter. Os valores de risco estão acima dos limites definidos pela U.S. EPA para avaliar as exposições que ocorrem com a ingestão de água, que, usando a Giardia como organismo de referência, estipulou que o risco microbiano fosse inferior a uma infecção por 10.000 pessoas por ano (WHO, 2001).

Os valores de risco elevados têm relação direta com a concentração de E. coli na água, que se apresentou elevada. Além disso, o uso da relação entre o número de patógenos e E. coli pode ter superestimado as concentrações de patógenos, visto que estas relações são provenientes de estudo realizado na Noruega, o qual pode não ser representativo das condições brasileiras.

A concentração estimada para Giardia e Cryptosporidium neste estudo está em acordo com o obtido por Mastropaulo e Razzolini (2018). Foi encontrada, em 53\% de 13 amostras analisadas de poços utilizados para abastecimento público em São Paulo, a presença de (oo) cistos de Cryptosporidium ou de Giardia. Ainda segundo os autores, uma amostra apresentou concentração de 0,6 oocistos/L de Cryptosporidium, enquanto em seis amostras foram detectados cistos de Giardia, apresentando concentrações entre $<0,1$ (Limite de detecção - LD) e 2,0 cistos/L. Nesta perspectiva, as concentrações variaram em uma frequência de $46 \%$ para Giardia e $7 \%$ para Cryptosporidium.

Neste estudo, as concentrações médias estimadas de Giardia e de Cryptosporidium foram de 0,91 oocistos/L e 0,84 cistos/L, respectivamente. Todavia, Mastropaulo e Razzolini (2018) afirmam que apenas 2,9\% das amostras indicaram a presença de coliformes termotolerantes e E. coli. Concomitantemente, não foi detectada $E$. coli nas amostras nas quais se realizou pesquisa de oo (cistos) de Cryptosporidium e de Giardia. Este fato evidencia as incertezas acerca das relações utilizadas.

Apesar das incertezas envolvidas no modelo proposto, em um cenário de limitação de recursos para a caracterização e quantificação dos patógenos diretamente, bem como um maior e mais detalhado número de coletas e análises, o modelo permite estimar o impacto na saúde da população usuária destes serviços e proporcionar informações importantes para a segurança da água.

Os valores obtidos da análise de risco são reflexo da alta concentração de coliformes fecais detectados na água, o que evidencia a degradação da fonte de água e o risco à saúde da população que consome essa água, em especial sem tratamento prévio.

\section{CONCLUSÕES}

Os resultados mostram que a água analisada se apresenta fora dos padrões de potabilidade definidos pela Portaria de Consolidação $n^{\circ}$ 5/2017 do Ministério da Saúde, em especial em relação aos parâmetros microbiológicos, que apresentaram valores elevados e acima dos valores máximos permitidos pela Portaria.

O risco anual de infecção para os patógenos Campylobacter, Giardia e Cryptosporidium apresentou valores críticos, se comparados ao valor considerado tolerável pela U.S. EPA.

Fica evidenciada a necessidade de se estabelecer um processo urgente de gerenciamento de risco, o que envolve o fornecimento de água em condições adequadas e seguras para a população residente nesta área.

Além disso, medidas de conscientização da população local, por meio de programas ou projetos de educação ambiental, podem ser importantes para que os moradores entendam o risco de se consumir a água dos poços rasos sem nenhum tratamento.

Adicionalmente, estudos futuros podem considerar a proximidade das fossas negras em relação aos poços rasos, bem como a direção da sua pluma de contaminação, o que não foi realizado nesse estudo.

\section{REFERÊNCIAS}

ALABURDA, J.; NISHIHARA, L. Presença de compostos de nitrogênio em águas de poços. Caderno de Saúde Pública, v. 32, n. $3, \quad 1998 . \quad$ https://doi.org/10.1590/S0034 89101998000200009

APHA. American Public Health Association. Standard methods for the examination of water and wastewater.

BARROS, R.C. Agricultura e sustentabilidade ambiental: a qualidade da água dos rios formadores da Bacia do Rio Grande Nova Friburgo/RJ. 2004. 243p. Tese (Doutorado em Geografia) - Universidade Federal do Rio de Janeiro, Rio de Janeiro, 2004.

BATAIERO, M.O. Ocorrência e caracterização de Giardia e Cryptosporidium em águas captadas para abastecimento público no município de Cajamar-SP e avaliação do risco. 2016. 148 p. Tese (Doutorado em Saúde Ambiental) - Faculdade de Saúde Pública, Universidade de São Paulo, São Paulo, 2016.

BRASIL. Ministério da Saúde. Fundação Nacional de Saúde. Manual de controle da qualidade da água para técnicos que 
trabalham em ETAS. Brasília, 2014.

BRASIL. Ministério da Saúde. Portaria de Consolidação $n^{\circ} 5$ de 28 de setembro de 2017. Anexo XX. Consolidação das normas sobre as ações e os serviços de saúde do Sistema Único de Saúde, 2017.

CAPP, N.; AYACH, L. R.; DOS SANTOS, T. M. B.; GUIMARÃES, S. T. L. Qualidade da água e fatores de contaminação de poços rasos na área urbana de Anastácio (MS). Geografia Ensino \& Pesquisa, v. 16, n. 3, set./dez. 2012. https://doi.org/10.5902/223649947581

CETESB. Companhia Ambiental do Estado de São Paulo. BRANDÃO, C. J. et al. (Orgs.). Guia nacional de coleta e preservação de amostras: água, sedimento, comunidades aquáticas e efluentes líquidos. São Paulo: CETESB; Brasília: ANA, 2011.

CETESB. Companhia Ambiental do Estado de São Paulo. Qualidade das águas subterrâneas do estado de São Paulo. Execução Rosângela Pacini Modesto... [et al.].; Colaboração Blas Marçal Sanchez et al. São Paulo, 2016.

CHUKWU, M. O.; ABIA, A. L. K.; UBOMBA-JASWA, E.; OBI, L.; DEWAR, J. B. Characterization and Phylogenetic Analysis of Campylobacter Species Isolated from Paediatric Stool and Water Samples in the Northwest Province, South Africa. Int. J. Environ. Res. Public Health, 2019. https://doi.org/10.3390/ijerph16122205

DE SOUZA, W. B.; MELO, L. P.; LIMA, L. C. S.; DE SOUZA, D. C.; TEXEIRA, T. T. Mapeamento e avaliação da potabilidade de água proveniente de fontes alternativas de captação na cidade de Astolfo Dutra. Águas Subterrâneas - Seção Estudos de Caso e Notas Técnicas, v. 32, n. 3, 2018. https://doi.org/10.14295/ras.v32i3.29179

EREGNO, F. E.; TRYLAND, I.; TJOMSLAND, T.; MYRMEL, M.; ROBERTSON, L.; HEISTAD, A. Quantitative microbial risk assessment combined with hydrodynamic modelling to estimate the public health risk associated with bathing after rainfall events. Elsevier B.V., Science of the Total Environment, p. 270 279, 2016. https://doi.org/10.1016/j.scitotenv.2016.01.034

FENZL, N.; MENDES, R. L. R.; FERNANDES, L. L. A sustentabilidade do sistema de abastecimento de água: da captação ao consumo de água de Belém. Belém: NUMA/UFPA, 2018. $153 p$.

FREGONESI, B. M.; SAMPAIO, C. F.; RAGAZZI, M. F.; TONANI, K. A. A.; SEGURA-MUÑOZ, S. I. Cryptosporidium e Giardia: desafios em águas de abastecimento público. O Mundo da Saúde, São Paulo, 2012. https://doi.org/10.15343/01047809.2012364602609

GIANPÁ, C.; GONÇALES, V. G. Orientações para a utilização de águas subterrâneas no estado de São Paulo. São Paulo: FIESP/ABAS, 2005

GOIÂNIA. Prefeitura Municipal de Goiânia. Bairros com população e sua área de abrangência por região - Goiânia - 2013. 2013. Dados online... Disponível em: http://www.goiania.go.gov.br/shtml/seplam/anuario2013/arquivos\%20anuario/3\%20DEMOGRAFIA/3.5\%20Popula\%C3\%A7\%C3\%A30\%20por\%20Bairros/3.5.3\%20Bairros $\% 20$ com $\% 20$ popula $\%$ C3\%A7\%C3\%A3o\%20e\%20sua $\% 20 \%$ C3\%A1rea $\% 20$ de
\%20abrang\%C3\%AAncia\%20\%20por\%20regi\%C3\%A30\%20\%20Goi\%C3\%A2nia\%20-\%202013.pdf. Acesso em: 26 nov. 2019.

GOIÂNIA. Prefeitura Municipal de Goiânia. Base de Dados de Georreferenciamento. Dados online... Disponível em: https://www12.goiania.go.gov.br/. Acesso em: 26 nov. 2019. GOIÂNIA. Prefeitura Municipal de Goiânia. Mapa Digital Fácil. Dados online... Disponível em: portalmapa.goiania.go.gov.br/mapafacil/. Acesso em: 26 nov. 2019.

HAAS, C.N.; ROSE, J. B.; GERBA, C. P. Quantitative microbial risk assessment. Toronto: John Willey \& sons, 1999.

HÉLLER, L.; DE PÁDUA, V. L. Abastecimento de água para consumo humano. Belo Horizonte: Editora UFMG, 2006.

IBGE. Instituto Brasileiro de Geografia e Estatística. Pesquisa de orçamentos familiares 2008-2009: antropometria e estado nutricional de crianças, adolescentes e adultos. Rio de Janeiro. 2010.

MACHDAR, E.; VAN DER STEEN, N. P.; RASCHID-SALLY, L.; LENS, P. N. L. Application of Quantitative Microbial Risk Assessment to analyze the public health risk from poor drinking water quality in a low income area in Accra, Ghana. Elsevier B.V. Science of the Total Environment, p. 134-142, 2013. https://doi.org/10.1016/i.scitotenv.2013.01.048

MADIGAN, M. T.; MARTINKO, J. M.; BENDER, K. S.; BUCKLEY, D. H.; STAHL, D. A. Microbiologia de Brock. 14. ed. Porto Alegre: Artmed Editora, p. 903-922, 2016.

MASTROPAULO, A. A.; RAZZOLNI, M. T. Qualidade da Água de Sistema Alternativo Coletivo de Abastecimento para Consumo Humano: Ocorrência de Cistos de Giardia e Oocistos de Cryptosporidium em Poços de São Paulo-SP. Revista Brasileira de Ciências da Saúde, v. 22, 2018. https://doi.org/10.4034/RBCS.2018.22.03.07

MOREIRA, J. C. F.; POMINI, P. C. C. Qualidade da água subterrânea no distrito do Riozinho Cacoal-RO. Revista Eletrônica FACIMEDIT, v. 6, n. 2, dez./jan. 2017.

RIBEIRO, P. G.; PEREIRA, I.; DOS SANTOS, C. C. A.; FRANCO, C. S.; MARQUES, R. F. P. V. Qualidade da Água Subterrânea e Tratamento Simplificado para Abastecimento Humano do Instituto Eterna Misericórdia de Lavras-MG. Revista Gestão \& Sustentabilidade Ambiental, v. 8, n. 3, p. 566-581, 2019. https://doi.org/10.19177/rgsa.v8e32019566-581

SALING, C.; GRAFF, A.; OLIVEIRA, E. C.; BOCKEL, W. J. Avaliação da Qualidade da Água em Poços Rasos no Município de Colinas - RS. Tecno-Lógica, Santa Cruz do Sul, v. 21, n. 2, p. 5964, jul./dez. 2017. https://doi.org/10.17058/tecnolog.v21i2.7901

SIEG. Sistema Estadual de Geoinformação de Goiás. Dados online... Downloads. Disponivel em: http://www.sieg.go.gov.br/siegdownloads/. Acesso em: 26 nov. 2019.

SILVA, S. A.; OLIVEIRA, R. Manual de análises físico-químicas de águas de abastecimento e residuárias. Campina Grande: DEC/CCT/UFPG, 2001. 
TEUNIS, P. F.; NAGELKERKE, N. J.; HAAS, C. N. Dose response models for infectious gastroenteritis. Risk Anal, v. 19, p. 12511260, 1999. 6924.1999.tb01143.x

U.S. EPA. Exposure Factors Handbook Chapter 3 (Update): ingestion of water and other select liquids. U.S. EPA Office of Research and Development, Washington, DC, EPA/600/R18/259F, 2019.

USMAN, M. A.; GERBER, N.; VON BRAUN, J. The Impact of Drinking Water Quality and Sanitation on Child Health: Evidence from Rural Ethiopia. The Journal of Development Studies, v. 55, p. 1-19, 2018.

WHO. World Health Organization. Guidelines, standards and health: assessment of risk and risk management for water-related infectious disease. 2001.
WHO. World Health Organization. Guidelines for drinking-water quality. WHO Chronicle, p. 38. 2011.

WHO. World Health Organization. Water sanitation hygiene: diseases and risks. 2014. Disponivel em: https://www.who.int/water_sanitation_health/diseasesrisks/en/. Acesso em: 25 nov. 2019.

WHO - World Health Organization. Quantitative Microbial Risk Assessment: application for water safety management. WHO Library Cataloguing-in-Publication Data. 2016. 